\title{
Student's perception of educational environment at an 'all female medical school' in Saudi Arabia.
}

\author{
Tabinda Hasan ${ }^{1}$, Thannaa Ibrahim ${ }^{1}$, Tehseen FM Ali ${ }^{2}$
}

\begin{abstract}
Background: Educational environment is defined as everything that happens within the classroom, faculty or university and is crucial for determining the success of medical education. Motivated learners in supportive environments demonstrate high levels of self-efficacy and performance. The educational environment is therefore crucial in determining the success of medical education.
\end{abstract}

Objectives: To ascertain student's perceptions regarding their learning environment at the newly established Jazan Women's Medical Faculty in order to identify strengths and weaknesses and design remedial measures for establishing a conductive pedagogical ethos in the institution.

Method: The validated tool, Dundee Ready Educational Environment Measure (DREEM) was administered to 40 medical students in the 3rd year.

Results: Mean DREEM score for the study group was $91.36 / 200$. The poorest scores were for Learning (19.28/48), Atmosphere(19.83/48) and Social (13.10/ 28) domains while best scores were for Teaching (22.80/ 44) and Academic(16.35/32) domains.

Conclusion: Our score is lower than global scores of most medical institutions of other countries and lies within league of 'generally poor scores' of a majority of contemporary Saudi medical schools which is a forewarning that some teaching-learning areas need improvement. There is a need to develop human resources and policy models in order to ensure and maintain quality in educational standards.

Key words: DREEM, Teaching, Learning

\section{Introduction}

The quality of the educational climate in any medical school determines the success of curriculum transaction, learning outcomes and ultimately, the framing of medical students as proficient healthcare providers. The World Federation for Medical Education (WFME) has singled out the educational environment as one of the most important targets for medical education evaluation programs.

\footnotetext{
${ }^{1}$ Faculty of Medicine, Jazan University, Saudi Arabia

${ }^{2}$ Applied Health Sciences, Jazan University, Saudi Arabia

Corresponding author:

Dr Tabinda Hasan

Department of Anatomy, Post box 114

Faculty of Medicine, Jazan University, Saudi Arabia

E mail: drtabindahasan@gmail.com
}

This is exemplified by Roff's quote, "Considerations of medical school climate, along lines of continuous quality improvement and innovation, are likely to further the medical school as a learning organization with true attendant benefits" (Roff et al.,1997). The contemporary medical education scenario of Saudi Arabia is witnessing an era of pedagogical revolution, with an up-sprouting of increased numbers of medical schools all over the country and a shift from traditional, didactic to integrated, problem based programs. During recent years, there has been a large scale expansion, diversification and electronification of medical education, while the impact of these developmental dynamics at the educational front still remains under assessed. Educational psychologists stand in unanimous agreement of the fact that the quality of educational environment determines the achievement of learning objectives as well as student's sense of well-being, confidence levels and 
professionalism. Particularly addressing this facet in the wake of current Saudi educational trends of federal emphasis on "females in higher education", our study ascertains students' perceptions regarding their learning environment at the newly established Jazan women's Medical Faculty. Such an in-depth qualitative analysis will provide objective evidence crucial for designing remedial measures for effective learning. Identification of program strengths and weaknesses will help establish a conductive pedagogical ethos in the institution that will hopefully contribute towards making better doctors.

\section{Methods}

We used a self-reported select response type structured survey instrument based on The Dundee Ready Educational Environment Measure (DREEM), (Roff et al., 1997). The meaning of key terms was explained to students prior to the administration. It was also explained that the data would be used for quality assurance and their co-operation was voluntary. Approval of the institutional ethical review board was taken before commencement of the study. The questionnaire consisted of 50 items, rated on a 5 point Likert scale, with a total score of 200 and consisting of the following subscales; Students' Perceptions of Learning (SPL); Students' Perceptions of Teachers (SPT); Students' Academic Self-Perceptions (SASP); Students' Perceptions of Atmosphere (SPA); Students' Social Self-Perceptions (SSSP). Each DREEM item was scored from 4 to 0 assigned for strongly agree, agree, uncertain, disagree and strongly disagree, respectively. Reverse scoring was used for negative items (number 25, 48, 8, 9, 39, 17, 35, 50, 4). Items with a mean score of 3 or above were taken as positive points and items with a mean score of 2 or below were taken as problem areas that needed rectification. Data was analyzed through statistical software SPSS version 17 ( $p$ value $<0.05$ significant)

\section{Results}

40 out of 45 medical students in the 3rd year took the survey. The overall mean DREEM score for the study group was 91.36 / 200. The mean DREEM scores for the domains SPL, SPT, SASP, SPA and SSSP were 19.28, $22.80,16.35,19.83$, and 13.10 respectively. The poorest scores were for SPL, SPA and SSSP domains while best scores were for SPT and SASP domains (Table 1 and Figure 1).

Table 1: DREEM domain scores for female medical undergraduate students (n=40); Academic year 2012

\begin{tabular}{lc}
\hline \multicolumn{1}{c}{ Domain / Maximum score } & Mean \pm SD \\
\hline Students perception of learning(SPL) / 48 & $19.28 \pm 6.11$ \\
Students perception of teaching(SPT) / 44 & $22.80 \pm 5.64$ \\
Student academic self perceptions (SASP) / 32 & $16.35 \pm 6.95$ \\
Students perception of atmosphere(SPA) / 48 & $19.83 \pm 7.16$ \\
Students social self perceptions(SSSP) / 28 & $13.10 \pm 5.11$ \\
\hline
\end{tabular}

Figure 1 - Percentage scores of DREEM domains for female medical undergraduate students (N=40)

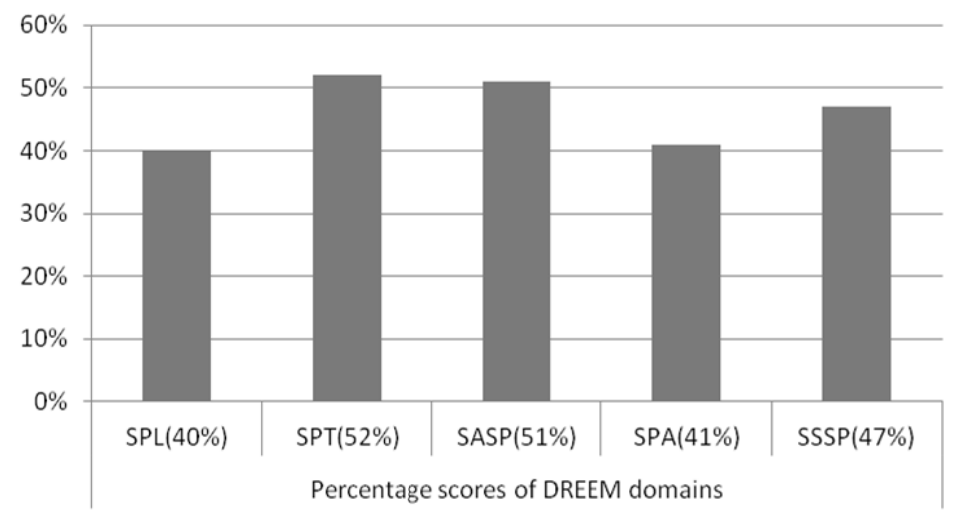


The group scored less than 2 (poor) for 30 items $(1,7,13,16,20,21,25,44,47,48,9$, $18,32,39,49,5,22,26,27,12,17,23,30$, $33,34,42,43,3,4,14)$ and more than 3 (good) for 2 items $(31,15)$ (Appendix 1).

\section{Discussion}

The educational environment is defined as everything that happens within the classroom, faculty or university and is crucial for determining the success of medical education. (Roff et al., 2001) Motivated learners in supportive environments demonstrate high levels of self-efficacy and performance. Our Mean DREEM score of 96.57 is lower than scores of most medical institutions in other countries; global DREEM scores for medical schools of India, Sri Lanka, Trinidad, Nepal, Nigeria and UK were reported to be 107,108 , $109.9,130,118$, and 139 respectively (Abraham et al., 2008; Varma et al., 2005). Published literature indicates overall mediocre median scores of around $60 \%$ or the like in most Saudi medical institutions which is a warning that some teaching - learning areas certainly need to be improved. (Al Rukban, 2010; Khan et al., 2010; Ayed et al., 2008; Makhdoom, 2009; Al Hazimi et al., 2004).

Considering that the Jazan Women's Medical college is relatively new; being established recently (in 2010), one might be tempted to assume that 'young' institutions such as ours are prone to such pedagogical lapses owing to inexperience. However, another similar study at our 'grand and well-settled neighbour' King Saud Medical College, Riyadh yielded similar low results (Ayed et al., 2008) which indicates that there are other factors beyond logistics, physical facilities and seniority status that govern educational environments. The scores for junior/pre-clinical King Saud students were significantly higher than senior/clinical year students.

In another report from a Thai nursing school, $14.8 \%$ of students rated their institution below $50 \%$ and generally the scores decreased from the first year to the second year and increased from second year to the third and fourth year on all five DREEM sub-scales (Pimparyon, 2000). The findings of an educational environment research at Guilan University of Medical Sciences, Iran in 2009 indicated that basic year students were more satisfied with their learning environment (as indicated by higher scores) than senior batch students (Taheri, 2009). Conversely, a study among Nepalese students reported a trend towards improved perceptions in second and third years over the first year (Roff, 2001). These contradicting patters of student opinions nullify the impression of certain researchers that perhaps basic year students are not 'experienced enough' to give a valid report of their educational process (Taheri, 2009) or that seniors are 'more critical' than juniors and student perceptions tend to spontaneously improve or deteriorate with passing academic years.

The study on Iranian students (Taheri, 2009) did not show any statistically significant differences between males and females for the DREEM subscales and total scores. This is in common with several other reports (Till, 2004; Ayed et al., 2008; Abraham et al., 2008) But it contradicts the results of an Argentinean study where a statistically significant difference between the sexes was observed; with women being generally more critical about the quality of teaching and the general climate of the school; especially in areas of students' participation in class and attitudes of teachers. Interestingly, women were reported as being far less satisfied with their social lives in college than men (Pimparyon, 2000).

Our students were stressed, with low confidence levels and poor social and academic support systems, similar to medical undergraduates of Sri Lanka (Lokuhetty et al., 2010) and India (Abraham et al., 2008). This could be due to stress, fatigue, apathy and 'too busy' teaching-learning trends of an overburdened system trying to cover 'too much in limited time'. Likewise, the social domain was among the poorest scoring areas, reflecting student's dissatisfaction regarding social self and institutional support system in a Birmingham Teaching Hospital of UK (Varma et al., 2005).

Teaching domain (SPT) reflected that teachers were generally viewed as well-informed and erudite but sarcastic and authoritarian. Significant differences exist between perceptions of academic achievers and underachievers (Mayya \& Roff, 2004) as compared to under-achievers, academic achievers have more positive perceptions regarding teachers and academic atmosphere which directly contributes to immersive, interactive learning. The irritable, impatient attitude of teachers in our faculty prompts some serious delving into underlying reasons; could work pressure of an elaborate 'academic with clinical teaching' framework be responsible for capricious attitudes among senior teachers? 
The other two poor scoring domains of our study group were learning (SPL) and atmosphere (SPA); indicating that teaching was viewed negatively by many students and the educational environment did not adequately involve or motivate students. Students expressed social discomfort, inability to clarify doubts, cheating problems and lack of interpersonal cohesiveness. Similar lags in social support systems have characteristically plagued medical under-graduates in other studies (Varma et al., 2005; Taheri, 2009; Lokuhetty et al., 2010) while it has been expressed as quite adequate and sustaining by still others (Abraham et al., 2008). Perhaps 'scholastic overburden' coupled with 'Laissezfaire' attitudes among key stake holders attributes to inadequate interpersonal bonding patterns and 'burn-out' amongst our community of scholars. Feasible and practicable solutions are needed to strengthen the social and emotional ethos of the institution.

The students in this study complained of an overemphasis on factual, teacher centered learning which corroborates the views of Iranian (Taheri, 2009) and Sri Lankan (Lokuhetty et al., 2010) students. Not being able to memorize 'all they need' and being 'unclear about learning objectives' was a general problem, which proposes a need for focused efforts in outlining core content and trimming down superfluous details by course organizers. It has been documented that students in traditional medical curricula perceived learning as being dogmatic and over emphasizing on 'rote memorization' leading to subsequent attrition. However, the Jazan medical curriculum is innovative and problem based and such divergence in learner behaviours needs further exploration to enable better understanding of student's insights. On a more positive note, our students agreed that course organizers conducted patient centred, community oriented discussions, were knowledgeable and came well prepared for the class. Likewise, favourable perception of teacher's competence has been observed in another inventory of Saudi diploma trainees (Khan et al., 2009).

Students were confident of their scholarly status and passing with good grades. They felt that they had gained relevant knowledge and professional empathy. This confidence boost appears to stem from growing familiarity and maturity in the medical field and has been observed among other senior students (Varma et al., 2005; Abraham et al., 2008; Taheri, 2009).
From the scanty literature that is available for Saudi Arabia, students here in general are more critical about the quality of teaching, especially in the areas of student participation in class and provision of clear learning objectives. Saudi students also perceive their course as being boring, tutor centred and fixedly attached to the module's timetable and without any 'comfort zones' of flexibility in schedules. Similar ratings among Indian medical students revealed that they were critical about the quality of teaching and the general climate of the school (Mayya \& Roff, 2004). Learning atmosphere and teachers' overall performance have generally received relatively higher scores in Saudi Arabia (Ayed et al., 2008; Khan et al., 2010).

Continuous quality improvement and pedagogical innovation are very essential in any medical institution and diagnostic inventories like DREEM act as a guiding resource for pedagogic planning and instructional innovation (Avalos et al., 2007) Further research on the use of the DREEM inventory, comparing different programs, study groups and follow up surveys may be useful for educators to ensure and maintain premium quality learning environments. This study benefited by specifically concentrating on female students which is of pivotal importance in the development and evaluation of modern medical curricula in league with current educational trends of Saudi Arabia with federal emphasis on 'female' higher education. A drawback of the study was an absence of simultaneous comparisons with male students, which might have elucidated certain gender differences in perceptions.

\section{Conclusion}

Despite assembling advanced educational delivery facilities, especially in terms of material resources, our scores are uniformly low, which necessitates probing into underlying reasons and redesigning our approach accordingly. Merely accumulating amenities and affluent physical infrastructure is not enough to build conductive pedagogical environments. There is a need to develop human resources and policy models in order to ensure quality in education and maintain uniformity in standards to facilitate the process of learning and assimilation of knowledge.

Remedial measures like student research projects, interactive and immersive teaching models, constructive feedback approach, personal and professional development 
programs or counselling sessions could develop students into independent learners, emotionally intelligent social beings, team workers and practical problem solvers. Teachers need to evolve from their 'closed box roles' of linear transmitters of knowledge into friends, mentors and guides if we hope to achieve desirable results.

\section{References}

Abraham, R., Ramnarayan, K., Vinod, P. \& Torke, S. (2008) Students' perceptions of learning environment in an Indian medical school, $B M C$ Medical Education, 8, 20.

Al-Hazimi, A., Zaini, R., Al-Hyiani, A., Hassan, N., Gunaid, A., Ponnamperuma, G., Karunathilake, I., Roff, S., McAleer, S. \& Davis M. (2004) Educational environment in traditional and innovative medical schools: A study in four undergraduate medical schools, Education for Health, 17, 2, pp.192-203.

Al Rukban, M.O., Khalil, M.S. \& Al-Zalabani, A. (2010) Learning environment in medical schools adopting different educational strategies, Academic Journals Educational Research and Reviews, 5, 3, pp.126-129.

Avalos, G., Freeman, C. \& Dunne, F. (2007) Determining the quality of the medical educational environment at an Irish medical school using the DREEM inventory, Irish Medical Journal,100, pp.522-525.

Ayed, I.H. \& Sheik, S.A. (2008) Assessment of the educational environment at the College of Medicine of King Saud University, Riyadh, Eastern Mediterranean Health Journal, 14, 4, pp.953-959.

Khan, A.S., Zekeriya, A. \& Tarek, M. (2010) Evaluation of the Learning Environment for Diploma in Family Medicine with the Dundee Ready Education Environment (DREEM) Inventory, Journal of Educational Evaluation for Health Professions, 7,2. doi: 10.3352/jeehp. 2010.7.2.
Lokuhetty, M.D.S., Warnakulasuriya, S.P., Perera, R.I.R., De Silva, H.T.R. \& Wijesinghe, H.D. (2010) Students' perception of the educational environment in a Medical Faculty with an innovative curriculum in Sri Lanka, South-East Asian Journal of Medical Education, 4, 1, pp.916.

Mayya, S.S. \& Roff, S. (2004) Students' perceptions of Educational Environment: A comparison of Academic Achievers and under- Achievers at Kasturba Medical College, India, Education for Health,17, 3, pp.280-291.

Makhdoom, N.M. (2009) Assessment of the Quality of Educational Climate During Undergraduate Clinical Teaching Years in the College of Medicine, Taibah University, Journal of Taibah University Medical Sciences, 4, 1, pp.42-52.

Pimparyon, P. (2000) Educational environment, student approaches to learning and academic achievement in a Thai nursing school, Medical Teacher, 22, 4, pp.359-365.

Roff, S., McAleer, S., Harden, R.M., Al-Qahtani, M., Ahmed, A.U., Deza, H., Groenen, G. \& Primparyon, P. (1997) Development and validation of the Dundee Ready Education Environment Measure (DREEM), Medical Teacher, 19, 4, pp.295-299.

Roff, S., McAleer, S., Ifere, O.S. \& Bhattacharya S. (2001) A global diagnostic tool for measuring educational environment: comparing Nigeria and Nepal, Medical Teacher, 23, 4, pp.378-382.

Taheri, M. (2009) Students' perceptions of learning environment in Guilan University of Medical Sciences, Journal of Medical Education, 13, 4, pp.126-133.

Till, H. (2004) Identifying the perceive weaknesses of new curriculum by means of the Dundee Ready Education Environment Measure (DREEM) Inventory, Medical Teacher, 26,1, pp.39-45.

Varma, R., Tiyagi, E. \& Gupta, J. (2005) Determining the quality of educational climate across multiple undergraduate teaching sites using the DREEM inventory, BMC Medical Education, 5,8, doi:10.1186/1472-6920-5-8. 


\section{Appendix 1}

DREEM 'item scores' for female medical undergraduate students ( $N=40)$; Academic year 2012; Faculty of medicine; Jazan University; KSA

\begin{tabular}{|c|c|}
\hline Item & Mean(SD) \\
\hline \multicolumn{2}{|l|}{ Students' perception of learning (SPL) } \\
\hline 1 I am encouraged to participate in teaching sessions & $1.05(0.93)$ \\
\hline 7 The teaching is often stimulating & $1.15(0.89)$ \\
\hline 13 The teaching is learner centred & $1.60(1.28)$ \\
\hline 16 The teaching helps to develop my competence & $1.73(1.04)$ \\
\hline 20 The teaching is well focused & $1.75(1.55)$ \\
\hline 21 The teaching helps to develop my confidence & $1.58(1.38)$ \\
\hline 24 The teaching time is put to good use & $2.15(1.46)$ \\
\hline 25 The teaching over emphasizes factual learning & $1.98(1.29)$ \\
\hline 38 I am clear about the learning objectives of the course & $2.08(1.35)$ \\
\hline 44 The teaching encourages me to be an active learner & $1.30(1.14)$ \\
\hline 47 Long term learning is emphasized over short term learning & $1.38(1.17)$ \\
\hline 48 The teaching is too teacher centred & $1.55(1.22)$ \\
\hline \multicolumn{2}{|l|}{ Students' perception of teaching (SPT) } \\
\hline 2 The course organizers are knowledgeable & $2.95(1.22)$ \\
\hline 6 The course organizers adopt a patient centred approach to discussions & $2.83(1.24)$ \\
\hline 8 The course organizers ridicule their learners & $2.10(1.06)$ \\
\hline 9 The course organizers are authoritarian & $1.53(1.22)$ \\
\hline 18 The course organizers appear to have effective communication skills & $1.73(1.18)$ \\
\hline 29 The course organizers are good at providing feedback & $2.00(1.30)$ \\
\hline 32 The course organizers provide constructive criticism & $1.53(1.24)$ \\
\hline 37 The course organizers give clear examples & $2.25(1.28)$ \\
\hline 39 The course organizers get angry in teaching sessions & $1.75(1.35)$ \\
\hline 40 The course organizers are well prepared for their teaching sessions & $2.63(1.36)$ \\
\hline 49 The learners irritate the course organizers & $1.73(1.22)$ \\
\hline \multicolumn{2}{|l|}{ Students' academic self-perceptions (SASP) } \\
\hline 5 Learning strategies which worked for me before continue to work for me now & 1.63(1.29) \\
\hline 10 I am confident about passing this year & $2.75(1.26)$ \\
\hline 22 I feel I am being well prepared for my profession & $1.53(1.32)$ \\
\hline 26 Last year's work has been a good preparation for this year's work & $1.39(1.15)$ \\
\hline 27 I am able to memorize all I need & $1.20(1.20)$ \\
\hline 31 I have learned a lot about empathy in my profession & $3.28(1.22)$ \\
\hline 41 My problem solving skills are being well developed here & $2.05(1.32)$ \\
\hline 45 Much of what I have to learn seems relevant to a career in healthcare & $2.60(1.35)$ \\
\hline
\end{tabular}




\begin{tabular}{ll}
\hline \multicolumn{1}{c}{ Item } & Mean(SD) \\
\hline Students' perception of atmosphere (SPA) & \\
\hline 11 The atmosphere is relaxed during consultation teaching & $2.48(1.32)$ \\
12 The course is well timetabled & $1.05(1.08)$ \\
17 Cheating is a problem in this course & $1.78(1.58)$ \\
23 The atmosphere is relaxed during lectures & $1.30(1.20)$ \\
30 There are opportunities for me to develop interpersonal skills & $1.25(1.26)$ \\
33 I feel comfortable in teaching sessions socially & $0.98(0.92)$ \\
34 The atmosphere is relaxed during seminars/tutorials & $1.28(1.41)$ \\
35 I find the experience disappointing & $2.10(1.65)$ \\
36 I am able to concentrate well & $2.05(1.18)$ \\
42 The enjoyment outweighs the stress of studying medicine & $1.68(1.61)$ \\
43 The atmosphere motivates me as a learner & $1.35(1.05)$ \\
50 I feel un-able to ask the questions I want & $2.55(1.34)$ \\
\hline Students' social self-perceptions (SSSP) & \\
\hline 3 There is a good support system for those who get stressed & $0.38(0.93)$ \\
4 I am too tired to enjoy this course & $1.65(1.64)$ \\
14 I am rarely bored during this course & $0.97(1.18)$ \\
15 I have good friends in this course & $3.08(1.26)$ \\
19 My social life is good & $2.78(1.31)$ \\
28 I seldom feel lonely & $2.35(1.51)$ \\
46 My accommodation is pleasant & $2.00(1.41)$ \\
\hline
\end{tabular}

